\title{
Benign Intracranial Hypertension
}

\section{A Review of 79 Cases in Infancy and Childhood}

\author{
D. N. GRANT \\ From the Department of Neurosurgery, The Hospital for Sick Children, Great Ormond Street, London
}

\begin{abstract}
Grant, D. N. (1971). Archives of Disease in Childhood, 46, 651. Benign intracranial hypertension: a review of 79 cases in infancy and childhood. An analysis is presented of 79 children under the age of 15 years suffering from benign intracranial hypertension. The commonest predisposing factor was chronic middle-ear disease which was found in $39 \%$. Headache was the presenting symptom in $57 \%$ followed in order of frequency by earache, blurred or double vision, and vomiting. Papilloedema was present at some stage in $95 \%$. Contrast radiography was regarded as mandatory in order to exclude a space-occupying lesion, the procedure of choice being ventriculography. A case is made for considering, as alternative procedures, echoencephalography or angiography. Treatment was limited to lumbar puncture and the prognosis was uniformly good. Nevertheless vigilance must be maintained because of the risk of permanent damage to vision from persistent papilloedema.
\end{abstract}

The syndrome of raised intracranial pressure in the absence of space-occupying lesion or obstruction to the cerebrospinal fluid pathways was first described by Quinke in 1893 . Otitis media was the most common single aetiological factor which was eventually recognized to be associated with the syndrome. The responsible mechanism was considered to be thrombosis of the major lateral venous sinus (Symonds, 1931). There remained, however a large number of cases in which no explanation was forthcoming, and to these Foley (1955) gave the name of benign intracranial hypertension. At the time of his review it was noted that the syndrome was associated with obesity, pregnancy, occasionally mild head injuries, and more tenuously after infections. Since then a number of other factors have been unequivocally incriminated in producing the syndrome. These include the drugs-tetracycline (Fields, 1961), chlortetracycline (Gellis, 1956), nalidixic acid (Boréus and Sundström, 1967), steroid hormones, particularly when withdrawn or diminished (Greer, 1963; Neville and Wilson, 1970), vitamin $A$ in excess (Marie and Sée, 1954), and also in deficiency (Keating and Feigin, 1970), Addison's disease (Walsh, 1952), iron deficiency anaemia (Lubeck, 1959), pernicious anaemia (Murphy and Costanzi, 1969), and hypo-

Received 26 April 1971. calcaemia (Sugar, 1953). In spite of the identification of these various aetiological agents, no explanation of the mechanism by which they cause raised intracranial pressure has been forthcoming. Though the age incidence of this condition shows one of two main peaks in the second decade, it remains an uncommon condition in childhood, and published series, particularly those devoted entirely to children, are infrequent and contain relatively small numbers of patients. Thus it is considered worth while to present a series of 79 children who were treated in a single neurosurgical unit. When Foley originally introduced the term 'benign intracranial hypertension', he applied it to cases without a history of middle-ear disease, reserving for them the admittedly unsuitable name of otitic hydrocephalus. By common usage, both otogenic and other cases now appear to be included in the same category and this is the nomenclature adopted in this series.

\section{Age and Sex Incidence}

Seventy-nine patients up to the age of 15 years, admitted to the neurosurgical unit of The Hospital for Sick Children between 1953 and 1970, were considered to be suffering from benign intracranial hypertension. The ages ranged from 4 months to $14 \frac{1}{2}$ years, the distribution being such 
that two-thirds lay between 4 and 10 years. There was no significant difference in sex incidence, $53 \%$ being male and $47 \%$ female. This is in contradistinction to series including all ages, in which there is a preponderance of females. This is probably related to hormonal influences when one considers the association of the syndrome with obesity, menorrhagia, pregnancy (Foley, 1955) and oral contraceptives (Walsh et al., 1965). This female preponderance is not noted when purely otitic cases are analysed.

\section{Presentation}

The commonest presenting symptom was headache occurring in $57 \%$ and it too was the commonest single complaint at any stage of the illness, being noted in $71 \%$ of children. Other presenting symptoms in order of frequency were: earache (11 children), visual complaints such as double vision, blurred vision, or soreness of eyes (7), vomiting (7), fits (4), aching legs (1), anorexia (1), vertigo (1). One child with no complaint whatsoever was found to have papilloedema at a routine school eye examination. Eye symptoms were present at some stage in $38 \%$. The duration of symptoms varied from 1 day to 2 years, with $54 \%$ being under 4 weeks.

\section{Associated Illnesses}

There was a history of middle-ear disease in 31 children (39\%). This varied in severity from recurrent earache responding to antibiotics locally or systemically, to chronic infection with discharge eventually requiring mastoidectomy. In one child the symptoms of recurrent otitis had existed for 7 years before the onset of intracranial hypertension. More usually the exacerbation of otitis media coincided with or preceded by some 4 to 6 weeks the onset of intracranial hypertension. Of the remaining known precipitating factors there were a few possible examples. Only one child had had a course of tetracyline over a 5-day period 2 months before admission. This, however, had been used as treatment for otitis media and it is more probable that the latter was the predominant cause. In 3 children the condition was associated with systemic steroid therapy. An 8-year-old boy had been treated for asthma with prednisone $2.5 \mathrm{mg}$ thrice daily for 5 months. He was admitted with a 3week history of headaches, vomiting, convergent squint, drowsiness, and hallucinations. A 6-yearold presented with a week's drowsiness and vomiting followed by headache. For the previous 2 years he had suffered from petit mal which came on after influenza. This was treated with phenobarbitone, phenytoin, and 2 courses of prednisolone. A 5- year-old boy who had been treated with steroids for arthritis of 2 years' duration presented with a month's history of headache and vomiting. On admission he was having prednisone $5 \mathrm{mg}$ twice a day which had resulted in an obvious moon facies. A baby aged 4 months, who had had infantile eczema since the age of 2 weeks, presented with a bulging anterior fontanelle, blurred disc margins, and an abnormal skull percussion note. These signs became obvious during a course of skin treatment with triamcinolone and betamethasone creams. Lumbar puncture showed CSF pressure to be $300 \mathrm{~mm}$. The occurrence of benign intracranial hypertension due to topical steroid application has been recorded by Benson and Pharoah (1960). One child of 8 years had had asthma since the age of 2. There was no information about steroid treatment. It is not inconceivable that chronic raised venous pressure might have had some influence on the development of benign intracranial hypertension. Bulging of the anterior fontanelle in infants with congestive cardiac failure has been documented (Silver, Kuskin, and Goldenberg, 1970). Reduced serum calcium $(8 \cdot 3 \mathrm{mg} /$ $100 \mathrm{ml}$ and $8.7 \mathrm{mg} / 100 \mathrm{ml}$ ) was discovered in a 7-year-old with a 2-month history of headache and abdominal pain. Three children had had head injuries which seemed probably related to the onset of intracranial hypertension. A 5-year-old girl suffered a mild head injury 7 weeks before admission; 2 days before admission she had a grand mal seizure. Her only abnormality was bilateral papilloedema. Ventriculography was normal. A 7year-old boy fell off a horse 3 months before admission and was found to have bilateral papilleodema at a school medical examination. An 11-year-old sustained a head injury at football. He was not unconscious but spent a week at home in bed complaining of headache and drowsiness. 7 weeks later he complained of vertigo and unsteadiness of gait. On examination he was found to have bilateral papilloedema with haemorrhages. Ventriculography showed no abnormality. Several children had histories of preceding febrile illness such as tonsillitis, measles, chicken-pox, and influenza.

\section{Signs}

On examination the optic discs were considered to be abnormal in all but 4 (i.e. in $95 \%$ ). The abnormality varied from blurring of the disc margins to gross papilloedema with haemorrhages. The $\mathbf{4}$ who did not have papilloedema on admission include 1 in whom this had been noted at the referring hospital but by the time of admission it had subsided; 1 in whom the admission was precipi- 
tated by earache, drowsiness, and vomiting and in whom the papilloedema appeared later during his stay in hospital, and 2 in whom papilloedema was never detected in spite of headache, vomiting, and ataxia of some weeks' duration. Other abnormal signs noted were unilateral external rectus palsy in 19 , bilateral external rectus palsy in 4 , bilateral extensor plantar responses in 6 , slight ataxia of the limbs in 7, mild unilateral facial weakness in 3, ankle clonus in 3 , and a wide-based gait in 2 , nystagmus in 1, limited upward gaze in 1, and a systolic bruit in both parietal regions in 1 child.

\section{Radiography}

Plain $x$-rays of the skull were done in every patient. No abnormality was detected in $45(51 \%)$. Opacity of the mastoid cells or of the middle ear was noted in $18(23 \%)$. Suture diastasis was present in $17(22 \%)$ and multiple fractures in 1.

The contrast study of choice was considered to be ventriculography because of the dangers of lumbar encephalography in the presence of raised intracranial pressure, particularly as many of these children were being investigated as having a possible space-occupying lesion. Ventriculography was carried out in 59 (i.e. $75 \%$ ). Of these 46 were normal, 7 showed mild dilatation, 2 showed slight asymmetry, and 4 failed. Lumbar encephalography was carried out in 21 (27\%) of whom 17 were normal. One showed ventricular dilatation, 2 showed cysts of the septum pellucidum, and 1 failed. Angiography was performed in 3-carotid in 3 instances, and in addition 1 child had vertebral angiography. With the exception of evidence of ventricular dilatation in 1 , these studies were normal. One radioactive brain scan was negative. The contrast study rate was $94 \%$. It is arguable that rather than proceed straight to ventriculography in the situation where benign intracranial hypertension is being considered, it would be preferable to start with echoencephalography and, if unequivocal evidence of normal or small lateral ventricles were obtained, to select lumbar encephalography as the definitive investigation. This would avoid the necessity of making burr-holes and the considerable difficulty sometimes experienced in puncturing small ventricles. Alternatively, angiography could be used as an initial investigation to confirm the normality of the ventricles. It is conceivable that with the increasing accuracy of brain scanning this might become a sufficient investigation for exclusion of space-occupying lesions.

Lumbar puncture was carried out on 31 patients more as a line of treatment than as a method of investigation. It was most frequently performed after air study at an interval varying from 1 to 10 days. Of those carried out before air studies, the range in pressure was from $140 \mathrm{~mm} \mathrm{CSF}$ to 550 $\mathrm{mm}$ CSF. The Queckenstedt manoeuvre was recorded in only a few instances when it was found to be normal. The quantity of CSF removed and the resulting fall in pressure were also not fully documented in more than a few instances. Removal of 10-15 ml was found to cause a drop from 450-150, removal of $20 \mathrm{ml}$ a drop from 550-250, and of $15 \mathrm{ml}$ a drop from $250-50$ on the 3 occasions when the records were complete. The Ayala Index, i.e. volume of fluid removed/resulting change in pressure, which was thought to be increased in so-called serous meningitis is of no value (Davson, 1967).

The ventricular CSF, excluding those which were contaminated by significant numbers of red blood cells, containing a varying amount of protein -in 13 patients it was below $10 \mathrm{mg} / 100 \mathrm{ml}$, in 6 between 10 and $20 \mathrm{mg} / 100 \mathrm{ml}$, in 5 between 20 and $30 \mathrm{mg} / 100 \mathrm{ml}$, in 3 between 30 and $40 \mathrm{mg} / 100$ $\mathrm{ml}$, and in 1 it was $125 \mathrm{mg} / 100 \mathrm{ml}$. The lumbar CSF protein in 22 instances was less than $30 \mathrm{mg} /$ $100 \mathrm{ml}$. In 1 patient in whom the ventricular CSF protein was $125 \mathrm{mg} / 100 \mathrm{ml}$, the lumbar value was $75 \mathrm{mg} / 100 \mathrm{ml}$ (1 week later) and in a further patient it was $80 \mathrm{mg} / 100 \mathrm{ml}$.

Electroencephalography was carried out in 51 patients and was reported to be abnormal in 48 . The abnormality was typically mild to moderate and diffuse, with sometimes asymmetry, and occasionally the posterior half of the head was noted to be more severely affected. The report occasionally stated that the changes were more consistent with a hemisphere disturbance than with a posterior fossa neoplasm which was frequently considered in the differential diagnosis.

\section{Treatment}

Treatment in the majority of children was entirely conservative, there being no single instance in which subtemporal decompression or suboccipital craniectomy was required because of visual deterioration. The majority had at least one lumbar puncture at which removal of even small quantities of fluid for diagnostic studies may coincidentally have been therapeutic. Where symptoms such as headache or vomiting and signs such as severe papilloedema failed to subside, repeated lumbar punctures were used, one particularly resistant child having lumbar punctures on alternate days or every third day for 2 months while in another hospital. One child was treated with dexamethazone and one with acetazolamide but there was 
nothing to suggest that their course was favourably influenced by such treatment.

\section{Follow-up}

The details of follow-up in these patients are exceedingly variable both in regard to the number of out-patient attendances in each individual case and to the total duration of surveillance. Some of the long-term follow-up information was obtained by letter from patients who by now have passed beyond the paediatric age group. In many instances the patients have been returned to the care of the referring paediatrician, and in view of the close liaison between the majority of the paediatricians and the neurosurgical unit, it may reasonably be assumed that any suspicion of recurrence of benign intracranial hypertension or onset of symptoms and signs suggestive of other neurological disease would have resulted in prompt return of the patient for further investigations. In these circumstances, I have assumed that any child who has been recorded at any time during the follow-up period as having returned to normal remains in that state as far as neurological illness is concerned, unless information to the contrary has been received.

In the series of 78 patients there has been one authentic recurrence of benign intracranial hypertension, i.e. two distinct episodes of abnormality separated by a period of unequivocal normality. This occurred in a boy who presented at the age of 13 years with a three-week history of headache, vomiting, and bilateral tinnitus. His only abnormal sign was bilateral papilloedema. Ventriculography showed no abnormality. At the second of two follow-up visits one year from discharge he was found to be normal. At the age of 16 years he was readmitted to another hospital with identical symptoms and once again was found to have papilloedema which only persisted for several days. This second attack appeared to have been precipitated by an upper respiratory tract infection. There were in addition 2 patients who required readmission-one a month after discharge and a second 3 weeks, 4 months, and 5 months from the initial discharge. These were examples of incomplete recovery rather than recurrence.

Follow-up information was obtained on at least one occasion in 56 of the 78 patients at varying intervals from 1 month to 15 years after discharge. At follow-up particular attention was paid to the fundi because of the possibility of permanent damage to the eyesight from persistent papilloedema. By one month after discharge, $47 \%$ of those patients who had been followed up were found to have normal fundi. At 2 months the figure was $48 \%$, at 6 months $54 \%$, at 1 year $67 \%$, at 2 years $75 \%$, at 3 years $85 \%$, and at 10 years $86 \%$. These figures express the well-known fact that the papilloedema eventually subsides completely in the majority of patients. Optic atrophy was found in two patients at 2 years and 4 years after the initial period in hospital. No record of visual acuity was obtained. In addition a grey appearance of the fundi was noted at 1 year in one patient. The other symptoms and signs of benign intracranial hypertension such as headache and strabismus appeared to recover more rapidly than the papilloedema. One patient at 7-year follow-up was said to have migraine. One 11-year-old girl died 9 months after discharge from leukaemia. In retrospect there was no evidence of this condition either in peripheral blood or in CSF.

\section{Discussion}

The importance of the condition of benign intracranial hypertension lies principally in three of its features. Firstly, in establishing the diagnosis, one is usually particularly concerned with the exclusion of a space-occupying lesion which is more likely to be the explanation of the signs of raised intracranial pressure in a child even in the absence of localizing neurological signs. It is for this reason that the diagnosis must still be made by exclusion except in occasional instances. For example, in those patients in whom the syndrome is associated with one of the recognized precipitating drugs, it may be permissible to dispense with complicated neuroradiological investigation if the signs regress steadily on withdrawal of the drug. Following such a policy in all cases, however, would sooner or later result in missing a space-occupying lesion.

Secondly, having established the diagnosis, the only concern appears to be to ensure that longcontinued raised intracranial pressure does not damage the eyesight. This appears to be less of a danger in children than in adults. None of the children in this series required decompressive operations for preservation of visual acuity but this has certainly been recorded in other series.

Thirdly, the condition is of theoretical interest in that there is presumably some underlying process common to the various aetiological types of benign intracranial hypertension. By further study of these patients fundamental information on the pathology and physiology of intracranial pressure may be obtained.

I should like to thank Sir Wylie McKissock and Mr. Kenneth Till under whose care these children were 
admitted to The Hospital for Sick Children, Great Ormond Street, for permission to review their cases and for their encouragement. I should also like to record my indebtedness to the Ingram Trust from whom I received a research grant.

\section{REFERENCES}

Benson, P. F., and Pharoah, P. O. D. (1960). Benign intracranial hypertension due to adrenal steroid therapy. Guy's Hospital Reports, 109, 212.

Boréus, L. O., and Sundström, B. (1967). Intracranial hypertension in a child during treatment with nalidixic acid. British Medical Fournal, $2,744$.

Davson, H. (1967). Physiology of the Cerebrospinal Fluid, p. 365. Churchill, London.

Fields, J. P. (1961). Bulging fontanelle: a complication of tetracycline therapy in infancy. Fournal of Pediatrics, 58, 74.

Foley, J. (1955). Benign forms of intracranial hypertension: 'toxic' and 'otitic' hydrocephalus. Brain, 78, 1.

Gellis, S. S. (1956). The Yearbook of Pediatrics, 1956-57, p. 40. The Year Book Publishers. Chicago.

Greer, M. (1963). Benign intracranial hypertension. II. Following corticosteroid therapy. Neurology (Minneapolis), 13, 439.

Keating, J. P., and Feigin, R. D. (1970). Increased intracranial pressure associated with probable vitamin $\mathbf{A}$ deficiency in cystic fibrosis. Pediatrics, 46, 41.

Lubeck, M. J. (1959). Papilledema caused by iron-deficiency anemia. Transactions of the American Academy of Ophthalmology, 63, 306.
Marie, J., and Sée, G. (1954). Acute hypervitaminosis A of the infant. American fournal of Diseases of Children, 87, 731.

Murphy, T. E., and Costanzi, J. J. (1969). Pseudotumor cerebri associated with pernicious anemia. Annals of Internal Medicine, 70, 777.

Neville, B. G. R., and Wilson, J. (1970). Benign intracranial hypertension following corticosteroid withdrawal in childhood. British Medical fournal, 3, 554.

Quincke, H. (1893). Uber Meningitis Serosa. Sammlung klinische Vorträge, 67 (Innere Medizin, 23), 655.

Silver, W., Kuskin, L., and Goldenberg, L. (1970). Bulging anterior fontanelle: sign of congestive heart failure in infants. Clinical Pediatrics, 9, 42.

Sugar, O. (1953). Central neurological complications of hypoparathyroidism. Archives of Neurology and Psychiatry, 70, 86.

Symonds, C. P. (1931). Otitic hydrocephalus. Brain, 54, 55.

Walsh, F. B. (1952). Papilledema associated with increased intracranial pressure in Addison's disease. Archives of Ophthalmology, 47, 86.

Walsh, F. B., Clark, D. B., Thompson, R. S., and Nicholson, D. H. (1965). Oral contraceptives and neuro-ophthalmologic interest. Archives of Ophthalmology, 74, 628.

Correspondence to D. N. Grant, F.R.C.S., Department of Neurosurgery, The Hospital for Sick Children, Great Ormond Street, London W.C.1. 